ARTIGOS

\title{
Política, Praxis e Pseudo-Atividade em Adorno ${ }^{1}$
}

\section{Politics, praxis and pseudo-activities in Adorno}

\author{
Wolfgang Leo Maar* \\ Universidade Federal de São Carlos - UFSCar, São Carlos, SP, Brasil
}

\begin{abstract}
RESUMO
Ao contrário da sua propalada aversão à práxis, Adorno situa em sua obra a prática em um nexo fundamental com suas posições teóricas e vice-versa. 0 objeto de sua apreensão teórica é a sociedade como auto-produção humana em todas as suas dimensões. As próprias formas sociais da sociedade são também socialmente produzidas. Assim a política não deve ser encarada como prática no plano da sociedade, mas no plano da produção histórica e social da mesma. $\mathrm{Na}$ sociedade vigente, as formas sociais parecem formas naturais perenes; o que seria práxis política se instala como pseudo-atividade de sujeitos assujeitados objetivamente numa ordem meramente adaptativa. Como construção do todo social verdadeiro, a política deve levar em conta estas determinações sociais que a condicionam na sociedade atual, decifrando-as em sua gênese; não pode prescindir da teoria para conferir objetividade à ação ao intervir na própria produção destas determinações.

Palavras-chave: Adorno e Práxis, Dialética de Teoria e Prática, Teoria Crítica e Política, Adorno e Objetividade Social.
\end{abstract}

\begin{abstract}
Although one finds very often assertions that Adorno has an aversion for praxis, this is a basic and foundational concept, articulated to Adorno's theoretical stand. The subject matter of Adorno's theoretical apprehensions is society understood as human self-production in all its dimensions. The social forms of society are, themselves, socially produced. Therefore politics should not be taken only as praxis on the realm of society, but it must be taken on the realm of its social and historical production. Social forms of the present society seem to be natural and immutable; what should be taken as political praxis appears as pseudo-activities of subjects that are objectively submitted to a merely adaptive order. Politics, as a construction of the true social whole, should take into account the social determinants of its existence in the present society, deciphering its genesis. Politics, to be objective in its actions to intervene in the determiners of its own production, cannot exist without theory.
\end{abstract}

Keywords: Adorno and Praxis, Dialectics of theory and praxis, Critical theory and politics, Adorno and social objectivity. 
1966. Véspera de Ano Novo. O repórter entrevista o famoso professor Adorno:

- O que deixa o senhor contrariado nas declarações da imprensa?

- Que eu seja cada vez mais avesso à prática, contrariando minhas próprias convicções teóricas.

(ADORNO, GS - Bd. 20-2, p. 737/8)

1. Antes de mais nada cabe enfatizar que Adorno foi muito atuante em intervenções públicas - em manifestações e atos públicos, em palestras, na imprensa escrita, no rádio, na televisão, em aulas - para discutir a situação política e social que lhe era contemporânea. Após seu retorno à Alemanha e bem antes de Marcuse, Adorno consolidara-se durante mais de uma década como destacado intelectual de esquerda engajado na vida pública. Assim posiciona-se muito além da empalidecida imagem que se possa ter de um simples professor com presença midiática, para nem mencionar o imobilismo enfeitiçado à beira do abismo sugerido por Lukács.

Contudo, mais do que meramente corrigir uma versão vigente de sua imagem, a resposta de Adorno pretendia destacar a perspectiva de apreensão da prática em sua obra de crítica social. Adorno situa explicitamente a prática em nexo fundamental com as suas posições teóricas. E neste contexto das relações entre teoria e prática - não seria por acaso que o título de um de seus últimos ensaios, postumamente publicado, é Notas acerca de teoria e prática (Marginalien zu Theorie und Praxis) - há que se aprender o prisma da política segundo Adorno. Apenas acompanhando a perspectiva da teoria crítica da sociedade de Adorno é possível apreender adequadamente a centralidade da prática segundo seu ponto de vista. Meu intuito aqui é destacar a perspectiva social e política apresentada por Adorno com a profundidade necessária e adequada à apreensão de sua maneira de delimitar a prática.

A grande contribuição de Adorno - e de todos os "frankfurtianos" da primeira geração, embora de maneira menos incisiva, exceção feita a Marcuse que nisso se identifica totalmente com Adorno - é apreender a realidade social como auto-produção humana em todas as suas dimensões. O "ser", aquele que, segundo a teoria, determina a "consciência", é ser histórico-social, auto-produzido pelos homens em sua interação social entre si e com a natureza, em sua práxis. Eis a nova objetividade filosófica que fora tomada pela "raiz" por Marx, o novo objeto que o mesmo decifra para concluir em razão disto que a 
"consciência" (Bewusstsein) a rigor se configura como "ser consciente" (bewusstes Sein); ou seja: ciência ou conhecimento de si da realidade efetiva desta autoprodução, para usar os termos com que Lukács se refere ao problema em História e Consciência de Classe.

Este é o objeto a quem Adorno confere prioridade. A teoria crítica de Adorno apreende a sociedade no seu processo de reprodução material e histórico, como mediação e não como fato imediato. I sto é: sempre já como resultado prático da ação determinada em formas sociais determinadas por indivíduos sociais determinados. O mundo dos homens já sempre é feito; como Adorno gostava de dizer: zugerichtet, usando o termo alemão de uso cotidiano para se referir, inclusive, à feitura de receitas culinárias.

Levada às suas últimas raízes, a perspectiva que diferencia prioritariamente Adorno é sua insistência em que também as formas sociais da sociedade já são socialmente determinadas, são objetivamente determinadas para serem determinantes no sentido da perenização prática da realidade objetiva vigente. Seria justamente esta dominação pela forma social em sua objetividade que impeliria Adorno a uma teoria estética. Por sua vez, segundo a perspectiva de Adorno, a política é a ação que leva em conta a objetividade destas determinações, atuando no próprio plano em que tais determinações se formam por ação dos homens no processo de reprodução social e material da sociedade.

Sua obra pode ser lida em grande parte como o decifrar da gênese, da produção histórica dessas determinações sociais objetivas do social e o refletir acerca das consequências dessa dupla determinação social da realidade nas várias esferas da atividade humana, seja no âmbito da política, seja no âmbito da cultura etc.

Para Adorno, no contexto de uma sociedade objetivamente determinada em sua forma social, como "um todo (que) é o não verdadeiro" conforme o parágrafo 29 da Minima Moralia (ADORNO, GS - Bd. 4, p. 55), a política no sentido de construção de um todo social verdadeiro só é efetiva quando diz respeito ao plano de produção DA sociedade, da produção das determinações sociais objetivas, e não quando é situada meramente NA sociedade, subordinada a determinações objetivas. Isto é: a praxis política precisa referir-se prioritariamente às determinações sociais objetivas da sociedade vigente.

Precisamente por isto a teoria é necessária para a perspectiva adequada da prática, decifrando as condições sociais objetivas da mesma. Neste sentido não existe somente uma identidade entre teoria e prática, mas também uma confrontação entre ambas, já que à teoria cabe fazer a crítica da prática objetivamente condicionada pelo vigente. 
Como se afirma em Notas acerca de teoria e prática, ao contrário do ponto de vista pragmático, a prática não é o critério de verdade da teoria (ADORNO, GS - Bd. 10-2, p. 189). O funcionamento real praticado na sociedade se dá sob determinadas determinações sociais cujos efeitos constituem a realidade social vigente; desse modo, o critério de verdade da prática está no contexto da adequada apreensão das determinações sociais da prática real, decifradas pela teoria crítica. Ele tem como núcleo histórico a possibilidade da negação determinada. Este primeiro momento da política, que é o da crítica da política vigente, não significaria, contudo, apenas uma política negativa, pela qual só se sabe o que não fazer. Esta é somente uma visão subjetiva do negativo, que se concentra na orientação dos sujeitos envolvidos tendo como baliza meramente a ordem vigente.

Mais importante e decisivo, porém, é que este negativo seja apreendido objetivamente, ou seja, apreendido no que se refere às determinações sociais objetivas da própria prática política daqueles sujeitos que são os indivíduos constituídos na sociedade vigente. Neste sentido, a política negativa não se orienta como práxis pelo que não deve ser feito, porque o feito é mera adequação reprodutora do vigente. Mas se orienta sim pelo que se há de fazer para negar praticamente uma realidade "negativa", determinada socialmente. Negar objetivamente as condições que, ao determinarem socialmente a política, obstruem a mesma pela adequação estrita à ordem imperante.

No dizer dos autores da Dialética do Esclarecimento:

Não é o bem mas o mal o objeto da teoria. Ela sempre pressupõe a reprodução da vida nas formas respectivamente determinadas. Seu elemento é a liberdade, seu tema a sujeição.

(ADORNO, GS - Bd. 3, p. 247)

O ponto de partida, o pressuposto que a rigor não é "pressuposto", é a reprodução da vida nas formas respectivamente determinadas. Ou seja: é o próprio processo de reprodução material. Mas este processo também é socialmente determinado, é uma mediação, a realidade da sujeição como liberdade negada.

Em outros termos: o "mal" já é efeito de uma prática, é uma realidade que conforme o prisma adorniano se encontra zugerichtet, adequada à continuidade da ordem vigente. Assim a prática objetivamente negativa da negação determinada se refere a uma realidade social determinada que é alienada; portanto trata-se de negar a negação. Para tanto se exige um referencial que ultrapasse o âmbito do estabelecido, possibilitando focalizar a própria produção das determinações sociais. É a isto que se refere o célebre lema que caracterizou os frankfurtianos: 
Nicht mitmachen! (Não coonestar pela participação!) É preciso desrespeitar o estabelecido, ultrapassar as formas sociais determinadas e consolidadas, tomando como foco justamente a o processo de produção social destas formas sociais. O tema surge na Dialética do Esclarecimento:

\begin{abstract}
Visto que a história enquanto correlato de uma teoria unitária, como algo de construível, não é o bem, mas justamente o horror, o pensamento na verdade é um elemento negativo. A esperança de uma melhoria das condições funda-se menos nas condições garantidas, estáveis e definitivas, do que precisamente na falta de respeito por tudo aquilo que está tão solidamente fundado no sofrimento geral. (ADORNO, GS - Bd. 3, p. 255/6)
\end{abstract}

Ecoa aqui de modo claro a "inexorável crítica" de Marx a todas "as condições que sujeitam os homens" da Introdução à Crítica da "Filosofia do Direito" de Hegel, pois também os homens não são "garantidos", mas socialmente gerados em determinadas condições. Também Adorno e Horkheimer, num movimento em direção à recuperação social e material do prisma dialético, referem o pensamento negativo ao plano constitutivo da esfera social determinada da adequação, ultrapassando o plano das "condições garantidas, estáveis e definitivas".

2. Desde o início o grupo de intelectuais reunido em torno ao Instituto de Pesquisa Social de Frankfurt conviveu com a questão das determinações objetivas das formas sociais da objetividade social. Ela pode até mesmo ser considerada o núcleo temático prioritário da teoria crítica da sociedade. O assunto preferencial da política dos anos vinte do século passado foi a constatação de que a figura do proletariado revolucionário, em que se depositara as esperanças da emancipação, ficara "invisível" (unsichtbar) no contexto de uma classe trabalhadora cada vez mais integrada e à vontade na sociedade capitalista. Este quadro corresponderia justamente a esta determinação social do social, no caso a própria força de trabalho apreendida no plano das forças produtivas. Por essa via, as forças produtivas se aproximam do próprio caráter de classe das relações sociais de produção, são por elas determinadas em sua forma social e dessa maneira obstruem a contradição entre ambas.

A determinação social das formas sociais constitui justamente a moldura que delimita o quadro de uma sociedade "totalmente administrada", de um "todo que é o não-verdadeiro", figuras da totalização da determinação social capitalista apreendida na teoria crítica. 
A perspectiva da prática em Adorno é um testemunho radical da onipresença da influência teórica de Marx. Como já enfatizado antes, quando este afirma na última de suas famosas Teses sobre Feuerbach que "os homens só interpretaram o mundo de modos diferentes, cabe transformá-lo", insiste na perspectiva histórica materialista de apreensão do mundo enquanto objeto auto-produzido pelos homens. Isso é, como produto de uma prática, "já transformado", a ser "transformado" e que só se pode "transformar a si próprio", isto é, em relação ao qual só se pode agir adequadamente nos termos de uma prática aprendida não como aplicação de um sujeito exterior à mesma, mas como práxis em que o nexo com o sujeito é imanente ao objeto.

Assim, ao revelar a construção objetiva da formação social presente, Adorno, ao contrário do resignado pessimismo equivocadamente associado à sua obra, apresenta, isto sim, uma alternativa prática real efetiva à tendência à totalização social dominante. Esta alternativa transita necessariamente pelo decifrar das determinações sociais resultantes da produção da realidade em que os homens se inserem e culmina com a negação determinada destas determinações.

A questão está presente logo no prefácio da Dialética do Esclarecimento, como divisor de águas da perspectiva da teoria crítica em relação às teorias marxistas da época. Assim afirmam Horkeimer e Adorno:

O que nos propusemos de fato não era nada menos do que apresentar o conhecimento de porque a humanidade, em vez de adentrar em uma situação verdadeiramente humana, afunda em um novo tipo de barbárie. Nós subestimamos a dificuldade da apresentação porque ainda confiávamos em demasia na consciência vigente. (ADORNO, GS - Bd. 3, 11).

Cabia desconfiar da "consciência vigente" e apreendê-la também no âmbito das determinações sociais objetivas do processo de reprodução da sociedade vigente. As próprias formas da ciência vigente são socialmente determinadas, ao mesmo tempo em que a ciência assim determinada é incapaz - porque foi gerada deste modo determinado de possibilitar a perspectiva da totalidade que facultaria a decifração dessas suas determinações sociais. Já Georg Lukács denunciara este problema em História e Consciência de Classe, desafiando o marxismo de viés cientificista da época a desenvolver um posicionamento crítico de que era incapaz.

Também na Minima Moralia, todo o esfôrço da apresentação da experiência individual particular em sua dialética de subjetividade e objetividade, pode também ser inserida nessa temática das determinações objetivas da subjetividade. As determinações objetivas 
teriam sido levadas tão a sério por Hegel - em sua crítica à moralidade, por exemplo - que, para parafrasear a conhecida frase de Adorno em relação a Freud, no exagero que é a aniquilação do particular subordinado à determinação da universalidade abstrata, reside a verdade de sua concepção como perspectiva da totalidade. Interessa a Hegel proporcionar, pela dialética, o nexo entre as formas sociais determinadas e o conteúdo efetivo a que correspondem, que se oculta naquelas formas. O tema aparece na obra hegeliana como nexo dialético entre o universal e o particular e é explicado por Adorno num trecho do seu livro Tres estudos sobre Hegel. Adorno explicita a questão a partir da dialética entre o particular e o universal na obra de Hegel.

O universal sempre é simultaneamente o particular e o particular, o universal. Na medida em que a dialética desdobra este nexo, ela corresponde ao campo de forças social: em que todo o individual já está pré-formado socialmente, mas em que também nada se realiza a não ser através dos indivíduos. (ADORNO, GS - Bd. 5, p. 289)

Na sociedade civil burguesa a relação entre o particular e o universal é antinômica. Hegel expressaria esta antinomia, segundo Adorno, pela nulidade que confere à aparência da individualidade real empírica em que se realizaria a liberdade burguesa, "o indivíduo gerado no contexto da ausência universal de liberdade como se já fosse livre e universal". (ADORNO, GS - Bd. 5, p. 290) No horizonte hegeliano não há, portanto, uma dissolução do nexo entre particular e universal, mas sim uma recusa da realização abstrata, ideal, da conciliação do particular e do universal na sociedade civil-burguesa.

Ainda nessa mesma direção cabe também acompanhar os derradeiros escritos de Adorno, em especial o já citado Notas acerca de teoria e prática. Aqui encontra-se uma síntese finamente elaborada da questão da prática e das determinações sociais objetivas do social.

A prioridade do objeto há que ser respeitada pela prática; em sua crítica à ética da convicção moral de Kant, o idealista Hegel assinalou isto pela primeira vez. Na medida em que o sujeito, ele próprio, por sua vez, é algo mediatizado, a prática apreendida corretamente é o que o objeto quer: ela segue as suas necessidades. Mas não mediante uma adaptação do sujeito, que meramente consolida a objetividade heterônoma. As necessidades do objeto são mediatizadas pelo sistema social como um todo; por isto só são determináveis criticamente por meio da teoria. A prática sem teoria, num plano inferior ao estado mais desenvolvido do conhecimento, é obrigada a não dar certo, e conforme seu conceito a prática pretende dar certo. 
Uma falsa prática não é prática. O desespero que, por encontrar barradas as saídas, impulsiona cegamente, apesar das melhores intenções termina por conduzir ao desastre. (ADORNO, GS Bd.10-2, p. 766)

O texto denso é extremamente didático. Transparece com toda clareza a imposição das "necessidades do objeto" na própria forma social do todo social. Indica-se o plano do conhecimento a ser adequadamente provido pela teoria em seu trabalho de decifrar as determinações que se apresentam mediatizadas no sistema social como um todo, na sociedade vigente como tal. Por isto impõe-se a necessidade da teoria em seu trabalho de interpretar, de esclarecer o conteúdo real que se abriga nesta forma social determinante. Adorno confere destaque a esta questão em um trecho um pouco adiante do texto citado, ao se referir ironicamente à leitura ingênua da última das Teses sobre Feuerbach, de que "os filósofos até então apenas interpretaram o mundo". A rigor esta "interpretação" decifra um outro contexto de "transformação" já realizada, aquela que, embora oculta e difusa, se encontra porém objetivada na forma social da sociedade vigente, reafirmando assim a tese de Marx numa escala a mais. A prática é a que deu certo na reprodução realizada do sistema social, embora como todo nãoverdadeiro. Este processo de reprodução deve ser o ponto de partida para apreender adequadamente as condições da prática, e não alguma "intenção" emancipatória, algum ideal a ser efetivado.

Há aqui um nítido materialismo presente, companheiro fiel de Adorno. Num protocolo de discussões acerca da dialética datado de 1939, publicado no volume 12 dos Escritos de Horkheimer, Adorno explicitara seu ponto de vista:

O conceito de dialética tem sido usado até hoje, inclusive na discussão marxista, de um modo essencialmente idealista, isto é, conclui-se a partir de um movimento conceitual e geral rumo ao movimento particular e específico na história (...) esta concepção é insuficiente, pois mesmo quando o conteúdo da doutrina afirma o contrário, por sua forma ela mantém a pretensão da subjetividade em dominar o mundo mediante seus conceitos. O problema da dialética, portanto, é determinado segundo dois aspectos: por um lado, a situação dada em que a reflexão deve se apoiar, também é constituída dialeticamente e não é um ponto de partida absoluto para a construção dialética. Por outro lado, esta construção dialética é inconseqüente, enquanto não estiver imediatamente presente a partir duma análise da situação dada. (HORKHEI MER, 1985, p. 527/8) 
Não só se parte de uma situação dada concreta, em vez de se subordinar a uma conceituação geral. Além disto esta situação dada não pode ser apresentada como absoluta, mas é também constituída. Por sua vez, a dialética só será efetiva se estiver presente nesta situação dada, e não for imposta exteriormente à mesma.

Existem assim duas dimensões a serem levadas em devida conta. Por um lado, o social precisa ser revelado na objetividade, em que ele se encontra congelado. Mas isto não basta, porque a forma deste social também é socialmente determinada. Impõe-se por outro lado, portanto, decifrar as determinações objetivas presentes nesta forma social. Há que se decifrar o conteúdo gerado como consequência destas formas determinadas, consequência que justifica as mesmas. O escopo da elaboração teórica dialética será assim decifrar o nexo em que as determinações sociais correspondem a determinadas realidades sociais. Ou seja, investigar a situação dada vigente na sua análise em sua gênese histórica, conforme a dinâmica de sua produção, em vez de pressupor uma interpretação que, embora dialética, fosse regressiva a partir do produto, partindo de formas sociais pressupostas e não elas próprias também produzidas.

Em Sujeito e Objeto, texto que precede e condiciona o ensaio Notas acerca de teoria e prática constituindo os Epilegômenos dialéticos, Adorno explicita mais detalhadamente esta elaboração teórica. Caberia decifrar as determinações objetivas deste momento subjetivo, evitando deter-se satisfeito na revelação simples do social presente na objetivação. Esta dupla reflexão social constitui a profundidade necessária para apreender a dialética da produção e da transformação histórica, para além da mera interpretação da sociedade já instalada. Adorno denominaria esta dupla reflexão de "segundo giro copernicano" (zweite kopernikanische Wendung) (ADORNO, GS - Bd. 10-2, p. 746) A questão encontra-se referida também na introdução da Dialética Negativa. (ADORNO, GS - Bd. 6, p. 10 ).

Não basta apenas referir-se ao momento subjetivo ou social presente na sociedade objetivada. Além disto este momento precisa ser decifrado em seus próprios momentos, também socialmente determinados em sua produção. Como se verá adiante, eis a verdadeira densidade do que é apreendido no âmbito do chamado "fetichismo da mercadoria". Adorno não se contenta em decifrar em sua objetividade o social que está subsumido no objeto aparentemente natural, na "segunda natureza". Mas procura, além disso, decifrar o social em sua subjetividade, revelando o momento subjetivo deste sujeito social, a gênese histórica da produção (o subjetivo) das formas sociais determinadas do social, a consciência burguesa. Não se trata de uma decifrar interpretativo 
regressivo, mas sim de uma explicação que revela o que é decifrado como uma produção - não "só" produto - socialmente determinada. Está em pauta aqui o valor de uso do trabalho enquanto mercadoria-trabalho que é também valor de troca. Mostra assim a contradição e as possibilidades desse social, a serem expostas pela práxis correspondente ao que, no plano conceitual, seria negação determinada da produção determinada.

O segundo giro copernicano não se limita a uma "dupla" reflexão. O "segundo" giro é uma inversão materialista da reflexão interpretativa dialética, inversão mediante a qual a interpretação dá lugar a uma investigação da gênese, da produção material histórica das objetivações a serem decifradas.

Eis aqui a inflexão teórica fundamental, que distingue Adorno de Hegel, substituindo a coruja vespertina da interpretação regressiva pelo galo matutino da produção histórica. A determinação social existente, embora alienada e entre outras possíveis, (o "mal" que é objeto da teoria) se dispõe no lugar da idealização futura do que seria determinante na situação emancipada (o "bem"), tomando agora como ponto de partida o próprio processo real de reprodução material, mas em sua base contraditória.

Haveria uma imposição social profunda no que chamamos a sociedade decorrente do processo, também ele socialmente determinado, pelo qual os seres humanos produzem materialmente. Adorno retomaria aqui um dos conceitos centrais da teoria marxiana: o fetichismo da mercadoria.

O problema do fetichismo da mercadoria não termina com a revelação do social na objetivação petrificada, mas conduz à necessidade de decifrar as determinações objetivas deste social, da própria "base" econômica, para usar uma terminologia bastante conhecida, pelas quais a própria produção, enquanto subjetividade, seria socialmente determinada de modo a preservar a continuidade do vigente, na medida em que lhe corresponderia uma determinada consciência. Adorno conduz a focalização do fetichismo da mercadoria à sua dimensão mais radical, perseguindo o problema até sua raiz. Assim, por exemplo, não bastaria se contentar com a revelação do sujeito social cuja objetivação seria obstruída no produto do trabalho; caberia decifrar as próprias formas sociais determinadas da realidade deste sujeito, sujeitado em sua forma social objetivamente à realidade vigente. Desta maneira se explicaria, por exemplo, o ocorrido em relação ao proletariado e que já foi mencionado anteriormente. Trata-se de um trabalhador coletivo numa forma social determinada conforme os interesses da continuidade das relações sociais vigentes. Caberia precisamente à teoria dialética decifrar o nexo entre a forma social em que se apresenta esse sujeito e 
o conteúdo material cuja consolidação corresponde, como resultado, a esta determinação social. Ao apreender a produção desta realidade, objetivada na forma social do sujeito adequado à reprodução da ordem vigente, Adorno facultaria a perspectiva de produção de formas sociais determinadas críticas à ordem vigente.

3. Primordial para Adorno é que não basta examinar política, prática ou cultura, tais como se verificam NA sociedade vigente. É preciso investigá-las tendo como referência o contexto de produção DA sociedade, enquanto formação social auto-gerada pelos homens e apreendida em sua dialética histórica. Embora a via régia de acesso ao essencial seja o processo de sua reprodução vigente em seu aparecer real, presente, cultura, moral e política, por exemplo, precisam ser examinadas por um ponto de vista apoiado fora do âmbito estritamente cultural, moral ou político tal como estes são estabelecidos na sociedade, para serem investigadas no plano da própria produção social da sociedade em sua forma determinada.

Não basta permanecer no plano da sujeição, restringir-se à sua "fenomenologia" (ADORNO, GS - Bd. 8, p. 100); é preciso avançar à própria produção deste plano, conforme uma "teoria mais ampla" (ADORNO, GS - Bd. 8, p. 94). No caso da moral, por exemplo, segundo Adorno é preciso responder à pergunta referente à produção histórica da sujeição, em vez de interpretar regressivamente, tendo como pressuposto a-crítico uma idealização da situação de não-sujeição. Essencial é saber "Como os homens se sujeitam a si próprios, impondo a si o imperativo categórico: 'Sujeita-te àquilo que existe!'?" (ADORNO, GS - Bd. 10-1, p. 343). Novamente importa sublinhar a grande proximidade entre as argumentações de Adorno e Marx. Este também iniciara pela investigação material-histórica e não conforme um referencial ideal pressuposto. Embora seu alvo fosse o trabalho como auto-produção humana, seu tema seria o "trabalho alienado". No primeiro de seus Manuscritos Econômico-Filosóficos indaga de um modo que por certo influenciou a pergunta de Adorno acima referida:

Aceitamos como um fato o estranhamento do trabalho, sua alienação e analisamos este fato. Agora indagamos: como o homem chega a estranhar, chega a alienar o seu trabalho? Como este estranhamento se funda na essência do desenvolvimento humano? (MARX; ENGELS, 1966, p. 86)

Os conceitos de indústria cultural e de semiformação procuram dar conta dos fenômenos da sociedade real vigente justamente tendo como 
referência o prisma de produção desta sociedade em sua formação social determinada.

O termo indústria cultural enfatiza de modo pertinente o "mecanismo" pelo qual a sociedade como um todo seria "construída" sob a égide do capital, reforçando a continuidade do vigente. Ao que tudo indica os autores pensaram, nos termos da produção pela indústria capitalista, na produção da sociedade como sendo cópia feita na medida em que a sociedade é cultural, ordena e organiza o que seria "natural". No ensaio Superstição de Segunda Mão Adorno resume de modo exemplar: “(...) a indústria cultural como um todo (...) duplica o que já existe na consciência dos homens." (ADORNO, GS - Bd. 8, p. 175). Eis a "cópia industrial-cultural" do mundo congelada na situação existente. Mas cumpre lembrar o decisivo: "consciência" é "ser consciente", isto é, reflexão da existência, e não uma existência espiritual contraposta dualisticamente à matéria "inconsciente".

O momento subjetivo deste social presente como cópia, como objetificação coisificada, seria decifrado já na primeira versão da Dialética do Esclarecimento como semiformação. Adorno diria mais tarde, em sua Teoria da Semiformação: "a cultura tomada pelo lado de sua apreensão subjetiva, é a formação". Nessa apreensão subjetiva da perspectiva da "cultura" nos termos da indústria cultural que copia a sociedade em estrita continuidade de sua vigência, a "consciência" reflete sobre a continuidade social como "semiformação", em nexo com uma cultura hegemônicamente "afirmativa", para usar aqui um tema caro a Marcuse (MARCUSE, 1997, p. 89).

Pelo prisma dos autores da Dialética do Esclarecimento, as "massas" são semiformadas afirmativamente, isto é, constituídas no processo de construção social para se integrarem justamente no contexto da reprodução continuada do vigente em que a indústria cultural ocupa um posto chave.

Neste contexto de determinação social objetiva da sociedade, da consciência, da cultura, que justamente era oferecido pela conceituação da indústria cultural, precisam ser situados adequadamente os referenciais da crítica ideológica em termos que alcancem além do âmbito da crítica cultural. É precisamente o que Adorno pretende no ensaio Crtítica Cultural e Sociedade.

Ao mesmo tempo em que desconsidera os efeitos da crítica cultural, apresenta sua nova apreensão de ideologia. O foco da análise é uma perspectiva de totalidade imanente, em que o todo se revela como falso em todos os seus momentos e os critérios desta falsidade são transcendentes a este todo, embora imanentes em relação à perspectiva de totalidade. 
Hoje a determinação da consciência pelo ser se converteu em meio de escamotear qualquer consciência que discorde da existência. (...) Ideologia significa hoje: a sociedade como aparência. Ela se encontra mediatizada pela totalidade, por trás da qual se encontra a dominação do parcial, que não é sem mais redutível a um interesse parcial, mas se distribui igualmente em todas as suas partes. A alternativa de questionar a cultura a partir de fora, sob o conceito amplo de ideologia, ou de confrontá-la com as normas que ela mesma cristaliza, não pode ser aceita pela teoria crítica (...) Hoje a ideologia, a aparência socialmente necessária, é a própria sociedade real (...) o procedimento imanente é o mais essencialmente dialético. Leva a sério o princípio de que o não verdadeiro não é a ideologia em si, mas a sua pretensão de coincidir com a realidade efetiva. (ADORNO, GS - Bd. 10-1, p. 23-27)

A crítica agora diria respeito a um todo falso, à construção cultural da sociedade onde a crítica cultural seria inofensiva. Haveria necessidade, portanto, de um prisma pelo qual este todo seria apreendido ele próprio como determinação social. O todo cultural é falso, mas a verdade seria apreendida pela perspectiva da totalidade que não se esgota em sua manifestação como todo cultural. "A crítica vigente da ideologia é antiquada" (Adorno, GS - Bd. 10-1, p. 29) porque ela não alcança seu próprio objeto, ou seja, a sociedade, que, como construção social, se desvela como sendo sua própria ideologia. Em Educação e Emancipação Adorno diria:

a própria organização do mundo em que vivemos é a ideologia dominante - hoje muito pouco parecida com uma determinada visão de mundo ou teoria - ou seja, a organização do mundo converteu-se a si mesma imediatamente em sua própria ideologia. Ela exerce uma pressão tão intensa sobre as pessoas que supera toda educação. (ADORNO, 1995, p. 143)

O falso nesta medida já não seria o ideológico propriamente dito, mas a pretensão deste mundo reconstruído como ideologia se apresentar como a sociedade efetiva. Não apenas uma parte, mas a sociedade como "um todo é o não-verdadeiro". Em outras palavras: o falso como "a propaganda a favor do mundo mediante a sua duplicação" integrada, adaptada. (Adorno, GS - Bd. 10-1, p. 29)

A "duplicação" mencionada não deve iludir: não estão em causa dois mundos, mas um movimento dialético entre aparência e essência. 0 mundo dos homens é organizado de determinada maneira e é preciso decifrar as condições e os condicionantes que causam seu modo determinado de ser. A essência não está "atrás" da aparência, mas é a 
reflexão da aparência acerca de seu modo de aparecer de determinado modo, o "arranjo" determinado do mundo, a sociedade que é sua própria ideologia. A emancipação, como "conscientização", é a reflexão racional pela qual o que parece ordem natural, "essencial" na sociedade cultural, se decifra como ordem socialmente determinada em determinadas condições da produção real efetiva da sociedade.

$\mathrm{Na}$ obra de Adorno estes dois momentos dialéticos se apresentam em diversas ocasiões.

$\mathrm{Na}$ Introdução à Sociologia, último curso oferecido por Adorno em 1969, pouco antes de falecer, as relações entre sociologia e economia política exemplificam o nexo entre o plano da sociedade constituída e o plano da sua produção que se pretende expor aqui.

Minha tese é simplesmente a seguinte: através da separação estrita entre Economia e Sociologia, feita sem a menos dúvida com o objetivo real de recusar a teoria marxista ante portas, desaparecem os interesses sociais decisivos de ambas as disciplinas (...) ambas malogram em relação ao que é decisivo para elas. A sociologia (...) restringe-se a opiniões e preferências, ou quando muito a relações interpessoais, formas sociais, instituições, relações de dominação e conflitos. Nessa medida passa-se ao largo do que seria propriamente a raison d'être de todas essas coisas (...) e que é o único padrão que possibilita sua avaliação; ou seja. Deixa-se de lado o processo de autoconservação da sociedade humana; não se leva em conta que afinal todo esse processo social gigantesco e mantido unido pela troca é absolutamente desprovido de qualquer sentido que não seja em primeiro lugar garantir e conservar em movimento, materialmente e em seu padrão cultural, a vida do gênero humano em seu conjunto. (...) Em outras palavras: a Sociologia (...) não leva em conta a produção e a reprodução social da vida da sociedade como um todo: e se existe algo que é uma relação social, então é justamente esta totalidade. (ADORNO, 2008, p. 320)

Antes de mais nada, sublinhemos mais uma vez a sincronia com a argumentação de Marx. No Capítulo IV - inédito este constatara que sua concepção era

essencialmente distinta da concepção dos economistas burgueses, enredados nas próprias representações burguesas, que, apesar de perceberem como se produz no interior da relação capitalista, não percebem como esta relação ela própria é produzida e deste modo se elimina o seu direito histórico como forma necessária do desenvolvimento econômico (MARX, 1969, p. 89) 
Tudo se passa como se estivéssemos simultaneamente em dois "planos" de ordenamento social, que são momentos no movimento dialético da sociedade efetiva. O plano da economia política, da produção social material efetiva, determinada, dos homens em sua interação entre si e com a natureza, conforme um determinado modo de produção socialmente determinado - que é o "plano" de ordenamento social da produção da sociedade, o "social". E o plano da sociedade constituída por este determinado modo, cuja própria organização retrata aquela determinada maneira em que os homens produzem no primeiro plano, parecendo ser a sociedade em que produzimos - o "plano" de ordenamento social da produção na sociedade, o âmbito da "sociologia".

4. A política só é efetiva quando se refere à produção DA sociedade e não se restringe à ação NA sociedade constituída. Nesta última, as próprias formas sociais determinadas se apresentam como formas naturais perenes, impelindo à conservação da ordem imperante pela ineficácia objetiva das práticas meramente subjetivas. No dizer de Adorno a política aqui é apenas pseudo-atividade, (ADORNO, 1969: 181), isto é, semi-praxis meramente adaptativa. As determinações sociais da realidade vigente recolonizam os ímpetos subjetivos de mudança, convertendo-os em meros apêndices inofensivos da própria continuidade da ordem instalada.

Em seu sentido de construção do todo social verdadeiro, a política deve levar em conta a determinação social que a condiciona na sociedade vigente. Adorno se dedica ao tema em várias oportunidades.

De um modo especialmente interessante isso ocorre ao tratar da questão representada por Auschwitz. A necessidade de que Auschwitz não se repita não se identifica ao imperativo categórico de que Auschwitz não deve se repetir. A configuração moral formal precisa dar lugar à crítica social da produção das condições que tornaram Auschwitz possível. O referencial da crítica que se pretende efetiva se sustenta no plano da gênese histórico-empírica da formação social em que Auschwitz foi gestado: o plano empírico sensorial do sofrimento, do horror, da fome.

Aqui se apresenta em toda clareza o que distingue a dialética interpretativa hegeliana e a dialética material-histórica de Adorno.

Hegel desenvolvera a perspectiva dialética em sua crítica à moralidade para procurar transcender a separação entre forma e conteúdo e decifrar nas formas o que seria seu recheio, seu conteúdo. Adorno partilha com Hegel em grande parte a sua crítica, como transparece em sua obra sobre o filósofo. 
Nele já se impõe a constatação de que (...) a consciência moral não propicia a ação reta e justa e que o mero aprofundamento do eu no que deve ou não deve ser feito se enreda em contrasenso e vaidade. Hegel leva em frente um impulso radical da Ilustração. Ele não contrapõe o bem à vida empírica como princípio abstrato, como idéia auto-suficiente, mas vincula o bem em seu próprio conteúdo à construção de um todo verdadeiro - justamente àquilo que na crítica da razão prática aparece sob a denominação de humanidade. Por esta via Hegel transcende a separação burguesa entre o ethos como uma determinação incondicionalmente obrigatória, mas apenas válida subjetivamente e a objetividade aparentemente apenas empírica da sociedade. (ADORNO, GS - Bd. 5, p. 291)

A crítica hegeliana da moral seria sublinhada numa caracterização quase "materialista" da objetividade empírica por Adorno, que reproduz o trecho da "moralidade" da Fenomenologia do Espírito:

O motivo pelo qual a assim chamada felicidade deve ser compartilhada com outros é a boa amizade, que se permite e deseja a eles e a si este acaso. (ADORNO, GS - Bd. 5, p. 292)

Segundo Adorno um burguês jamais raciocinaria assim, pois ao enaltecimento da ordem vigente corresponderia também a ilusão de que o indivíduo esteja de posse da realização do bem, "de modo que a apologia da sociedade, para se manter em sua injustiça, depende da ideologia moral do indivíduo e de sua renúncia à felicidade" (ADORNO, GS - Bd.5: p. 292). Sublinhe-se aqui, antes de mais nada, o quanto já existe em Hegel relativo à perspectiva da apreensão da moralidade pelos seus efeitos, isto é, a ideologia moral como condição da sociedade nos termos que seriam posteriormente encampados fortemente por Nietzsche.

Mas a partir deste ponto Adorno abandona a argumentação hegeliana. Afasta-se mesmo polarmente da mesma na própria dinâmica da dialética.

Para Hegel a interpretação chega a seu termo no próprio plano em que se apresenta a questão moral. Segundo ele a reflexão acerca da forma social assumida na moralidade burguesa conduziria à superação dessa determinação formal numa determinação de conteúdo. Existiria assim uma "solução" no plano em que se instituiu a moralidade.

Mas para Adorno a produção histórica da sociedade implica em que a própria moralidade seja questionada juntamente com o indivíduo burgues, mostrando, como o fez Marx, que o mesmo movimento que gera o burgues, também gera o "populacho"(Pöbel), e que assim o que Hegel, em sua lógica conceitual, considerava uma cisão inevitável na 
sociedade civil, correspondia a uma situação historicamente desenvolvida e historicamente evitável.

Voltando ao nosso argumento inicial: evitar a repetição de Auschwitz requer para Adorno superar o plano do ativismo moral pela perspectiva da produção da própria sociedade em suas formas determinadas. A formalidade universal do imperativo categórico seria incompatível com o efetivo enfrentamento de Auschwitz.

A mesma questão pode ser acompanhada em outra ocasião na obra de Adorno: quando este discute a fome. A citação é da Introdução ao debate do positivismo na sociologia alemã, um dos últimos ensaios de Adorno.

Os problemas normativos erguem-se a partir de constelações históricas que de igual maneira exigem silenciosa e "objetivamente" a partir de si próprias sua transformação ... Não seria possível, por exemplo, decretar abstratamente que todos os homens precisam ter o que comer enquanto as forças produtivas não fossem suficientes para a satisfação das necessidades primitivas de todos. Contudo, quando numa sociedade aqui e agora, em face da abundância de bens existentes ... da mesma maneira existe a fome, então isto exige a abolição da fome pela intervenção nas relações de produção. Esta exigência brota da situação, de sua análise em todas as dimensões, sem que para isto se precisasse da universalidade e da necessidade de uma representação de valor. (ADORNO, GS Bd.8, p. 347; ADORNO, 1999, p. 183)

A ação moral corresponde à presumida autonomia do indivíduo, de há muito dissolvida. Mas não está em jogo recuperar essa autonomia, nem sequer explicar porque desapareceu.

O prisma proposto e que confere fluidez à argumentação de Adorno procede a partir dos efeitos praticados e não das intenções idealizadas. Como carência, a fome seria argumentativamente retirada do plano natural, para ser situada inteiramente no plano da sociedade formada, gerada em determinadas relações sociais de produção. Quando há fome socialmente motivada, a decretação moral abstrata e formal do fim da fome fortalece uma conformação social sustentada no exercício da autonomia nos parâmetros sociais vigentes, por mais heterônoma que esta seja. A moralidade subjetiva, que procura esgotar o campo de possibilidades da prática social, termina por encorpar uma ilusória formação social pacificada, em que os homens se julgam sujeitos e como tais se consideram responsáveis pela ordem vigente, para além das determinações objetivas que os sujeitam. 
Obstrui-se assim a apreensão da gênese histórica da própria orientação normativa, em especial, e das determinações sociais, como um todo, no quadro da produção da sociedade na forma social determinada em que se encontra na realidade imperante.

Já a intervenção nas relações de produção significa a intervenção no plano em que se produzem as próprias determinações sociais objetivas, as "constelações históricas" de que brotam tanto as questões normativas quanto as exigências de sua transformação. Aqui a negação não pode ser absoluta, generalizada, pois deixaria de incidir na determinação social. Cabe lembrar que para Adorno ideologia é a própria sociedade. O que está em causa não é o mundo, mas sua ordem determinada, seu "arranjo" nos termos de um determinado modo de sua reprodução material. A negação precisa ser negação determinada daquelas determinações sociais objetivas que "negam", que obstruem a própria prática, a própria "negação" possível neste plano.

Para concluir: tanto no que se refere a Auschwitz, quanto no referente ao problema da fome, o ativismo ético constitui para Adorno o que denomina uma "pseudo-atividade" (ADORNO, GS - Bd. 10-2, p. 771) que funciona como obstáculo à prática transformadora, renovando a ordem estabelecida mediante a consolidação das determinações sociais objetivas correspondentes a determinadas relações de produção.

5. Naquela que se tornaria sua última aula na Universidade de Frankfurt, Adorno ainda se referiu mais uma vez aos termos da forma socialmente determinada da determinação social objetiva, bem como ao conhecimento da inserção social dos homens e das mulheres nos termos da produção efetiva, material histórica, da sociedade.

O contexto específico da discussão era a influência exercida por dois grandes eventos midiáticos: o casamento da princesa herdeira da Holanda com um alemão e a visita de uma princesa persa à Alemanha. O fenômeno da personalização funcionaria como catalizador da reconstrução cultural industrial pacificadora e adaptativa da formação social.

A meu ver a tarefa mais importante da pesquisa social empírica hoje seria descobrir realmente até que ponto os homens efetivamente são e pensam nos termos em que são formados pelos mecanismos. A partir de trabalhos feitos no Instituto de Pesquisa Social (...) temos elementos que indicam a existência de uma curiosa ambigüidade. Isto é, que, de um lado, os homens se subordinam aos mecanismos da personalização como estes são promovidos pela indústria cultural (...). Mas, ao mesmo tempo, basta avançar um pouco além da superfície (...), todos os homens a rigor sabem que a princesa (...) não tem 
toda esta terrível importância. Se isso de fato ocorrer, se os homens efetivamente são envolvidos, mas simultaneamente também não o são, se portanto há aqui uma consciência duplicada e em si mesma contraditória, isto poderia ser a base de apoio do esclarecimento social que é necessário diante do fenômeno da personalização, que evidentemente é apenas parte de um contexto muito mais amplo, para esclarecer as pessoas de maneira exitosa de que o fundamental que lhes é imposto na sociedade (...) na realidade nem de longe tema a relevância que Ihe é imputada. (ADORNO, 2008, p. 343)

Para Adorno está em causa nada além de uma negação determinada no horizonte das possibilidades. Ele anuncia aqui a falsidade aparentemente revelada do consolo ofertado pelo fenômeno social da personalização frente à totalização da sociedade de massas. Ao mesmo tempo o tema da determinação social objetiva permanece em outras esferas de pseudo-atividade, onde os homens e as mulheres podem participar em suas próprias formas do estado de encantamento geral, sob as continuadas formas das suas determinações objetivas.

Às fases industrial-cultural e ética sucederia agora uma fase tecnológica. Aqui a sujeição e a impotência seriam dissolvidas na construção de uma aparente onipotência tecnológica, que pressupõe sujeitos autônomos inexistentes nos mesmos termos em que isto ocorrera no plano do imperativo moral. Nesta medida é "relevante para a pseudo-atividade a navegação espacial dos astronautas, que se orientam conforme os medidores de seus instrumentos e seguem minuciosamente ordens do comando central" (ADORNO, GS - Bd.102, p. 772).

Tanto os recentes "espetáculos" bélicos e de manipulação da opinião púbica do império americano, quanto, num extremo apenas aparentemente oposto, a sofisticação tecnológica do terrorismo, são formas contemporâneas das determinações sociais objetivas neste sentido.

Mas, essa fase tecnológica de reconstrução social legitimadora da ordem vigente também se apresenta pela via do esvaziamento da atividade político-participativa nas sociedades contemporâneas, associada à progressiva tecnicização formalista e jurisdicista da democracia, que corresponde, por sua vez, justamente a um controle mediante a manipulação tecnológica pelos meios de comunicação de massa em dimensões jamais vistas.

Simultaneamente, enorme parcela da humanidade morre de inanição; tem negada uma necessidade básica à sua reprodução.

O argumento de Adorno acerca da fome é hoje mais atual do que nunca. 
Em vez de se debaterem entre, de um lado, a realidade ficcional da hiper-tecnologia e da sociedade controlada pela manipulação da informação e da comunicação e, de outro, a realidade do desemprego, da miséria e da fome, os homens, afinal, sabem que a perspectiva para alterar este duplo quadro está em intervir no próprio processo de produção de que este mundo aqui e agora resultou.

\section{Referências Bibliográficas}

ADORNO, T. Wiesengrund - Gesammelte Schriften, In: 20 Bde. Darmstadt: Wissenschaftliche Buchgesellschaft - 1997. Citado como GS.

. Introdução à Sociologia. São Paulo: Edunesp - 2008. alemã", In:
Cultural - $19 \overline{9} \overline{9}$.

. Educação e Emancipação. São Paulo: Paz e Terra - 1995.

HORKHEIMER, M. Gesammelte Schriften - Bd.12. Frankfurt a. M.: Fischer, 1985.

MARCUSE, H. Cultura e Sociedade - 1. São Paulo: Paz e Terra 1997.

MARX, K. Resultate des unmittelbaren Produktionsprozesses. Frankfurt a. M.: Verlag Neue Kritik, 1969.

MARX, K.; ENGELS, F. Studienausgabe - Bd.2. Frankfurt a. M.: Fischer, 1966.

\section{Endereço para correspondência}

Wolfgang Leo Maar

Rua Monte Alegre, 1352, apto.4, Perdizes, CEP 05014-002, São Paulo- SP, Brasil

Endereço eletrônico: wmaar@ufscar.br

Recebido em: 31/05/2010

Aceito para publicação em: 15/07/2010

Acompanhamento do processo editorial: Ariane P. Ewald e Jorge Coelho Soares

\section{Notas}

${ }^{*}$ Professor titular de filosofia da Universidade Federal de São Carlos - UFSCar, São Carlos, SP, Brasil

${ }^{1}$ Uma versão preliminar e parcial deste artigo foi apresentada no Instituto Goethe de São Paulo em 2003, por ocasião do centenário de Adorno discutido no Ciclo de Debates Adorno Hoje, promoção do Instituto Goethe em colaboração com Unesp, Unicamp e USP. 